Portland State University

PDXScholar

Environmental Science and Management

Faculty Publications and Presentations

$12-1989$

\title{
Frequency-Dependent Seed Dispersal by Ants of Two Deciduous Forest Herbs
}

\author{
Brent H. Smith \\ Earlham College \\ Catherine E. de Rivera \\ Portland State University, derivera@pdx.edu \\ Cara Lin Bridgman \\ Earlham College \\ John J. Woid \\ Earlham College
}

Follow this and additional works at: https://pdxscholar.library.pdx.edu/esm_fac

Part of the Ecology and Evolutionary Biology Commons, Environmental Sciences Commons, and the Plant Sciences Commons

Let us know how access to this document benefits you.

\section{Citation Details}

Brent H. Smith, Catherine E. deRivera, Cara Lin Bridgman, and John J. Woida 1989. Frequency-Dependent Seed Dispersal by Ants of Two Deciduous Forest Herbs. Ecology 70:1645-1648.

This Article is brought to you for free and open access. It has been accepted for inclusion in Environmental Science and Management Faculty Publications and Presentations by an authorized administrator of PDXScholar. Please contact us if we can make this document more accessible: pdxscholar@pdx.edu. 


\title{
FREQUENCY-DEPENDENT SEED DISPERSAL BY ANTS OF TWO DECIDUOUS FOREST HERBS ${ }^{1}$
}

\author{
Brent H. Smith, Catherine E. DeRivera, Cara Lin Bridgman, and John J. Woida \\ Department of Biology, Earlham College, Richmond, Indiana 47374 USA
}

\begin{abstract}
Two co-occurring deciduous forest myrmecochores, Asarum canadense and Jeffersonia diphylla, release their seeds at approximately the same time, and therefore potentially compete for ants as dispersers. Within a single woodlot, we placed seeds of both species inside a dense Jeffersonia population away from Asarum plants, inside a dense Asarum population away from Jeffersonia plants, and in a site where plants of neither species occurred. No preference was exhibited by ants where natural populations were absent. Preference at the other two sites was frequency dependent: ants preferred seeds of the introduced species. Species preferred by ants have higher seed and seedling survival because by being carried into ant nests they escape predation and avoid nutrient deficiency. Implications of frequency-dependent dispersal are discussed.
\end{abstract}

Key words: ant-plant interaction; Asarum canadense; deciduous forest herbs; density dependent; frequency dependent; Indiana; Jeffersonia diphylla; myrmecochory; seed dispersal.

\section{INTRODUCTION}

The seeds of many spring-flowering perennial herbs of deciduous forests in eastern North America are dispersed by ants (Beattie and Culver 1981, Handel et al. 1981), in a mutualism characterized by a low degree of specificity between individual ant and plant species (Handel 1976, Culver and Beattie 1978, Beattie et al. 1979). Although there are temporal differences in seed release among some spatially co-occurring ant-dispersed herbs, several species make their seeds available to ants at approximately the same time (B. Smith, personal observation). Thus, some myrmecochorous plant species could potentially compete for ants as dispersers, with the "winner" being the species with the preferred seed.

Preference for seeds (or fruits) by animal vectors has been widely documented in some seed dispersal mutualisms (e.g., Smith and Follmer 1972, Moermond and Denslow 1983, Levey 1987), but few such studies have been conducted on co-occurring myrmecochores (but see Culver and Beattie 1978, Beattie et al. 1979). Conceivably, preferences by ants (if indeed there are preferences) may hinge on characteristics of the individual diaspore (Beattie et al. 1979), such as elaiosome size and nutritional content, diaspore-carrying mass, etc. It is also possible that seed preference varies depending on the absolute and relative densities of different kinds of seeds present in a local area. In this paper we investigate whether ants do indeed prefer seeds of one species over another, and in particular, whether preference varies with differences in the local seed environment.

The two species we studied are Asarum canadense and Jeffersonia diphylla (hereafter referred to as Asa-

\footnotetext{
${ }^{1}$ Manuscript received 5 August 1988; revised and accepted 13 March 1989.
}

rum and Jeffersonia). Both species are spring-flowering, clonal, perennial herbs whose seeds are dispersed by several species of ants. Both species release their seeds at approximately the same time in early June. Asarum bears its flowers at ground level. Once ripe, the six-celled capsule dehisces and ants can then begin extracting seeds from it. The fruiting capsule of Jeffersonia is borne on a leafless stalk. The top of the capsule functions as a lid formed by a fissure in the ovary wall. At maturity the lid opens and the distal end of the peduncle bends, spilling seeds to the ground. Predation by rodents on seeds within capsules, and after capsule dehiscence, may be quite heavy on both species, and occurs primarily at night (Heithaus 1981 , Smith et al. 1986).

The seeds of both species bear a fleshy elaiosome. Previous work on other species has shown that elaiosomes are rich in lipids, elicit seed-carrying behavior by ants, and provide a nutritional reward for them (Bresinsky 1963, Marshall et al. 1979). Ants typically deposit the seeds unharmed in the nest refuse pile underground once the elaiosome is consumed (Culver and Beattie 1978, 1980). Asarum seeds are smaller than those of Jeffersonia (mean [ $N=20$ seeds] fresh mass: Asarum $=14.2 \mathrm{mg}$, Jeffersonia $=30.0 \mathrm{mg}$; mean dry mass: Asarum $=6.8 \mathrm{mg}$, Jeffersonia $=14.9 \mathrm{mg}$ ). Fresh Asarum seeds offer a higher proportion of total seed mass in elaiosome tissue ( Asarum $=21.7 \%$, Jeffersonia $=3.8 \%$ ), but when calculated on a dry mass basis, percent elaiosome mass is virtually the same (Asarum $=6.2 \%$, Jeffersonia $=6.1 \%)$. Hence, on a fresh mass basis, Asarum offers more elaiosome tissue per seed, but on a dry mass basis, Jeffersonia has more.

\section{MeTHODS}

Our observations and experiments were conducted in Wildman's Woods, a mature deciduous forest lo- 
cated $5 \mathrm{~km}$ west of Richmond in east-central Indiana. Wildman's Woods is dominated by Acer sacharrum, Carya cordiformis, and Quercus rubra, and has a diverse understory, including Claytonia virginica, Trillium grandiflorum, Uvularia grandiflora, Hepatica acutiloba, Smilacina racemosa, Sanguinaria canadensis, and Thalictrum thalictroides. Both Asarum and Jeffersonia are common in this woods.

We measured the phenology of capsule dehiscence by censusing fruits of Asarum $(N=75)$ and Jeffersonia $(N=125)$ at $2-3$ d intervals from the time that capsules began to ripen until all had dehisced. An Asarum capsule was considered dehisced when the capsule wall had split open sufficiently wide to allow ants to enter and extract seeds; Jeffersonia capsules were declared dehisced when at least half of the seeds within them had fallen out. Abortion and predation of capsules prior to dehiscence were also noted.

A seed removal experiment was conducted at three study sites in which we placed seeds of Asarum and Jeffersonia in different combinations. The three study sites were chosen based on the presence/absence of extant Asarum and Jeffersonia populations. The "Jeffersonia site" was located in a dense population of Jeffersonia $\left(\right.$ mean $=17$ ramets $\left./ \mathrm{m}^{2}\right), 5 \mathrm{~m}$ away from the nearest Asarum individual. The "Asarum site" averaged 15 Asarum ramets $/ \mathrm{m}^{2}$, and was located $\approx 30 \mathrm{~m}$ from the nearest Jeffersonia population. A third site, the "North site," had neither Asarum nor Jeffersonia populations nearby $(>25 \mathrm{~m})$. Within each site, we constructed nine $0.5 \times 0.5 \mathrm{~m}$ quadrats $\approx 2 \mathrm{~m}$ apart. Three quadrats were randomly assigned as Jeffersonia "pure" quadrats, and three as Asarum "pure" quadrats, in which only Jeffersonia or Asarum seeds were placed and censused. The three remaining quadrats were "mixed" quadrats where seeds of both species were offered, and were used to compare with pure quadrats to see if ants exhibit preferences at small spatial scales. A few days prior to the experiment, depots (seed presentation sites) of $\approx 2 \mathrm{dm}^{2}$ were made in each quadrat by removing the litter and smoothing and compacting the soil to facilitate subsequent seed counting. Each pure quadrat had four depots, one at each corner. Each mixed quadrat had eight depots, $0.25 \mathrm{~m}$ apart, positioned around the quadrat perimeter, and Asarum and Jeffersonia seeds were placed in alternating depots for a total of four depots per quadrat for each species.

Overall, then, our design was a three-factor complete block experiment, with site (presence/absence of natural populations of Asarum or Jeffersonia), species of seed (Asarum or Jeffersonia), and pure-mixed quadrats as factors. Within each site, species, and pure-mixed treatment, there were three replicate quadrats each with four depots. Hence, an individual quadrat is a subsample within a site/species/pure-mixed treatment, and is treated as a nested factor within the three main factors in our data analysis.

The seeds used in the seed removal experiment were collected in Wildman's Woods and refrigerated for a few days prior to use. We initiated the experiment at 0700 on 17 June 1988 by placing 14 seeds of either Asarum or Jeffersonia at each depot. Seeds in all depots were censused at 1300 and 1900 that day. We noted any signs of rodent predation (empty seed coats, broken seeds) at these two censuses and at 0700 the next day (18 June).

The number of seeds remaining at a depot at 1900 was analyzed using three-way analysis of variance. We first did a nested ANOVA to test for differences in the number of seeds removed between replicate quadrats within sites/species/pure-mixed treatments. The results of this test were not significant $(F=1.43, P=$ .11 ), indicating that seed dispersal at the scale of a few square metres was not patchy. We then pooled the replicate quadrats for tests of main effects and factor interaction terms in the statistical model.

\section{RESULTS}

Both Asarum and Jeffersonia dehisce their capsules in early June, making their seeds available to ants at approximately the same time during the growing season (Fig. 1). Asarum capsules begin to dehisce before Jeffersonia, and dehiscence was much less synchronous than Jeffersonia. The midpoint of seed release by the two species, however, occurred at virtually the same time (7 June, Fig. 1). Prior to dehiscence, 37\% (46 of 125 ) of the Jeffersonia capsules were eaten by rodents. A predated capsule typically was removed from its stalk and could often be found at the base of the plant with a hole chewed in its side, and with empty seed coats and bits of broken seeds nearby. Only 1 of the 75 Asarum capsules (1.3\%) was eaten prior to seed release, but predation of capsules by rodents was as high as $51 \%$ in populations studied in other woodlots in the vicinity (B. Smith, personal observation).

The effects of the three factors of site, species of seed, and pure-mixed quadrats and their interactions on seed removal are shown in Table 1 and Fig. 2. The most interesting result is the highly significant statistical interaction found between sites and species of seed (site $\times$ species, Table 1). Asarum and Jeffersonia seeds were removed at approximately the same rate in the North site where natural populations of both species are absent (Fig. 2, Table 2). However, Jeffersonia was much preferred over Asarum within the Asarum site, and Asarum seeds were removed at a greater rate than Jeffersonia seeds in the Jeffersonia site (Fig. 2, Table 2). It is this interaction between site and species of seed that is responsible for the significant main effect of site shown in Table 1. When the species-of-seed and puremixed factors are pooled, seed removal rates are higher in the North site than within either the Jeffersonia or Asarum sites. However, the seed removal rates of the two species combined in the North site and the preferred species in the other sites (Asarum in the Jeffer- 


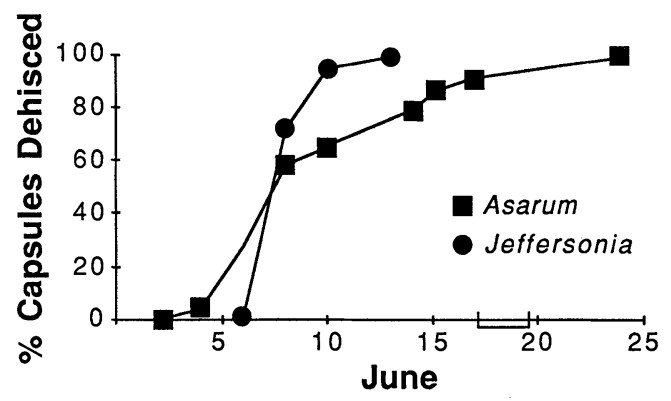

Fig. 1. The phenology of capsule dehiscence of Asarum canadense and Jeffersonia diphylla at Wildman's Woods. The bracket on the $x$-axis marks the time period of the seed removal experiment.

sonia site, Jeffersonia in the Asarum site) did not differ $(P=.08$, one-way ANOVA).

Seed removal did not differ between pure and mixed quadrats for either species, nor did ant preference for either Asarum or Jeffersonia differ among the pure and mixed quadrats (i.e., species $\times$ pure-mixed interaction; Tables 1, 2).

Finally, we found evidence of rodent predation (empty seed coats, bits of endosperm) at several Asarum and Jeffersonia depots, but only during the morning (0700) census on 18 June, indicating that rodent activity occurs largely at night, and that both Asarum and Jeffersonia seeds are taken.

\section{DisCUSSION}

Our results show that the probability that either an Asarum or Jeffersonia seed is removed by an ant depends on the density and species composition of the seed environment in which it is found. A seed that occurs in a site with low total seed density (e.g., the North site) is likely to be dispersed regardless of whether seeds of the other species are present at that site. In a denser seed environment, however, dispersal is frequency dependent: a seed is more likely to be dispersed by an ant if seeds of its species are rare relative to the other species.
TABLE 1. Three-way ANOVA comparing seed removal from depots at three different sites (North, Asarum, and Jeffersonia sites), of two different species (Asarum canadense and Jeffersonia diphylla) in pure and mixed quadrats on 1900 , 17 June.

\begin{tabular}{lcc}
\hline \hline & $F$ & $P$ \\
\hline Main effects & & \\
Site (S) & 5.06 & .008 \\
Species of seed (Sp) & 0.81 & .37 \\
Pure-mixed (P-M) & 0.04 & .85 \\
Interactions & & \\
S $\times$ Sp & 23.03 & $<.001$ \\
S $\times$ P-M & 0.68 & .51 \\
Sp $\times$ P-M & 1.16 & .28 \\
S $\times$ Sp $\times$ P-M & 0.17 & .85 \\
\hline
\end{tabular}

From the ant's perspective, our results suggest that the nutritional contents of Asarum and Jeffersonia elaiosomes differ qualitatively, and ants can and do discriminate between them. In this case, "preference" for the rare species is based on increased rejection of seeds of the abundant species, caused, probably, by satiation. Thus, ants do have preferences, but those preferences are not constant over space. Instead, preference probably hinges on the degree and kind of dietary satiation experienced by local ant populations.

A few studies have investigated whether ants discriminate between myrmecochores. Beattie et al. (1979) noted a slight tendency for larger ant species to take larger seeds and vice versa, but concluded that there was a general lack of specificity between ants and seeds. In a cafeteria experiment where seeds of several Viola species were offered simultaneously, Culver and Beattie (1978) found that ants preferred certain species, but preferences varied between woods. They did not, however, report what the seed environment was like within their experimental plots. Heithaus (1986) found that ants preferred Sanguinaria canadensis over Asarum when both were placed within Asarum populations when Asarum seeds were available naturally. No explanation for the preference was offered, but this may be an example of ants favoring the rarer species, similar
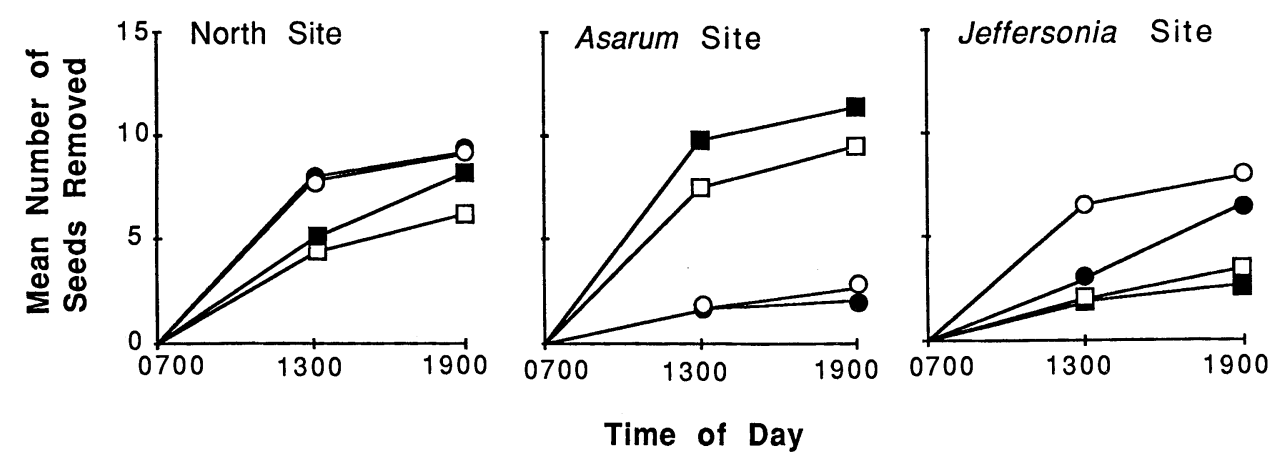

FIG. 2. Mean number of Asarum and Jeffersonia seeds removed per seed depot ( $N=12$ depots in all cases) in pure and mixed quadrats within the North site (outside of populations of Asarum and Jeffersonia), the Asarum site (within an Asarum population), and the Jeffersonia site (within a Jeffersonia population). Experiment was conducted on 17 June 1988. Symbols: - pure quadrats, Asarum seeds; $\bigcirc$ mixed quadrats, Asarum seeds; $\square$ pure quadrats, Jeffersonia seeds; $\square$ mixed quadrats, Jeffersonia seeds. 
TABLE 2. Two-way ANOVAs comparing seed removal of two species (Asarum canadense and Jeffersonia diphylla) in pure and mixed quadrats in each of three sites on 1900, 17 June.

\begin{tabular}{lcc}
\hline \hline & $F$ & $P$ \\
\hline North site & & \\
Species of seed (Sp) & 1.73 & .20 \\
Pure-mixed (P-M) & 0.47 & .50 \\
Sp × P-M & 0.55 & .46 \\
Asarum site & & \\
Species of seed & 49.40 & $<.001$ \\
Pure-mixed & 0.25 & .62 \\
Sp $\times$ P-M & 1.16 & .29 \\
Jeffersonia site & & \\
Species of seed & 8.03 & .01 \\
Pure-mixed & 0.60 & .44 \\
Sp $\times$ P-M & 0.02 & .89 \\
\hline
\end{tabular}

to our findings here. Working with two Trillium species (T. grandiflorum and T. sessile), B. H. Smith (unpublished manuscript) found that while seed removal was reduced where local seed densities were high, ants exhibited no preferences when seeds were placed eithe inside or outside of populations of either species. Seed and elaiosome size are, however, virtually the same for these two species, and given that they are related, it is possible that elaiosomes do not differ substantially in chemical content.

At this point, we cannot assess how common frequency-dependent seed dispersal is among temporally and spatially co-occurring myrmecochores. If indeed it is common, some interesting implications emerge Preference for certain seeds by ants does have a bearing on plant fitness beyond the benefits to fitness associated with dispersal away from the parent plant. Asarum anc Jeffersonia seeds are often heavily preyed on by rodents after capsules dehisce and seeds are made available tc ants (Heithaus 1981, Smith et al. 1986; Results section of this paper). The longer a seed is exposed above ground, the less attractive it is to ants (Smith et al 1986), and the more likely the seed will have been detected and consumed by rodents (Culver and Beattie 1978, Heithaus 1981, Smith et al. 1986). Thus, the timing of seed removal by ants to the comparative safety of their underground nests is critical, and a preferred species will have higher seed survival. Even i: predation rates are low, seeds of the preferred species will still be carried into an ant nest more frequently. This is advantageous because nests are nutrient-rich germination and establishment sites (Culver and Beattie 1978, 1980, Beattie and Culver 1983).

Given that ant dispersal of a rarer species of seed is more frequent, and that seed and seedling survivorship of the preferred species is higher, it is at least possible that local population sizes of rare species would increase over time to some equilibrium density dictated by ant activity and local competitive interactions among juvenile and established plants. Such a scenario would result in coexistence of the species involved, not competitive exclusion. The fate of seeds once they are removed by ants and germinate, however, is largely unknown. More research, particularly on the dynamics of seedling establishment, is needed before the ecological significance of frequency-dependent seed dispersal can be assessed.

\section{ÁCKNOWLEDGMENTS}

We thank W. H. Buskirk for helpful comments on the manuscript and A. E. Boyd and P. D. Forman for their assistance in various phases of this investigation. This research was funded in part by a grant from the Ford Foundation to Earlham College, and from additional funds provided by the College.

\section{Literature Cited}

Beattie, A. J., and D. C. Culver. 1981. The guild of myrmecochores in the herbaceous flora of West Virginia forests. Ecology 62:107-115.

Beattie, A. J., and D. C. Culver. 1983. The nest chemistry of two seed-dispersing ant species. Oecologia (Berlin) 56: 99-103.

Beattie, A. J., D. C. Culver, and R. J. Pudlo. 1979. Interactions between ants and the diaspores of some common spring flowering herbs in West Virginia. Castanea 44:177186.

Bresinsky, A. 1963. Bau, Entwicklungsgeschichte und Inhaltsstoffe der Elaiosomen. Studien zur myrmekochoren Verbreitung von Samen und Fruchten. Bibliotheca Botanica 126:1-54.

Culver, D. C., and A. J. Beattie. 1978. Myrmecochory in Viola: dynamics of seed-ant interactions in some West Virginia species. Journal of Ecology 66:53-72.

Culver, D. C., and A. J. Beattie. 1980. The fate of Viola seeds dispersed by ants. American Journal of Botany 67: 710-714.

Handel, S. N. 1976. Dispersal ecology of Carex pedunculata (Cyperaceae), a new North American myrmecochore. American Journal of Botany 63:1071-1079.

Handel, S. N., S. B. Fisch, and G. E. Schatz. 1981. Ants disperse a majority of herbs in a mesic forest community in New York State. Bulletin of the Torrey Botanical Club 108:430-437.

$\rightarrow$ Heithaus, E. R. 1981. Seed predation by rodents on three ant-dispersed plants. Ecology 62:136-145.

1986. Seed dispersal mutualism and the population density of Asarum canadense, an ant-dispersed plant. Pages 199-210 in A. Estrada and T. H. Fleming, editors. Frugivores and seed dispersal. Dr. W. Junk, Dordrecht, The Netherlands.

Levey, D. J. 1987. Sugar-tasting ability and fruit selection in tropical fruit-eating birds. Auk 104:173-179.

$\rightarrow$ Marshall, D. L., A. J. Beattie, and W. E. Bollenbacher. 1979. Evidence for diglycerides as attractants in an ant-seed interaction. Journal of Chemical Ecology 5:335-344.

$\rightarrow$ Moermond, T. C., and J. S. Denslow. 1983. Fruit choice in neotropical birds: effects of fruit type and accessibility on selectivity. Journal of Animal Ecology 52:407-420.

$\rightarrow$ Smith, C. C., and D. Follmer. 1972. Food preferences of squirrels. Ecology 53:82-91.

Smith, B. H., M. L. Ronsheim, and K. R. Swartz. 1986 Reproductive ecology of Jeffersonia diphylla (Berberidaceae). American Journal of Botany 73:1416-1426. 